\title{
Bíblia e Liturgia: da Providentissimus Deus à Evangelii Gaudium
}

\author{
Bible and Liturgy: \\ from Providentissimus Deus to Evangelii Gaudium
}

Marcelo Massao Osava

\section{Resumo}

O objetivo deste trabalho é fazer uma revisão dos principais documentos do magistério católico a respeito do estudo e intepretação da Palavra de Deus: Providentissimus Deus, Spiritus Paraclitus, Divino Afflante Spiritu, Sacrosanctum Concilium e Dei Verbum. Acrescentando ainda as preciosas contribuições da Vicesimus quintus annus, Verbum Domini e Evangelii Gaudium, será possível constatar como ao longo do tempo o magistério católico, impulsionado por movimentos de reforma bíblica e litúrgica, foi criando condições para que a comunidade cristã retornasse de maneira gradativa e de forma consciente para o texto sagrado, sobretudo revalorizando a Sagrada Escritura no interior das celebrações litúrgicas. Ao longo do trabalho os documentos do magistério irão ser expostos e revisitados (alguns documentos são mais conhecidos como, por exemplo, a Dei Verbum e outros nem tanto, como a Providentissimus Deus) de modo que seja possível esboçar uma avaliação sobre como está sendo vivenciada nas celebrações litúrgicas a relação entre Palavra de Deus e Sagrada Liturgia.

Palavras-chave: Bíblia. Liturgia. Magistério Católico.

\begin{abstract}
The purpose of this work is to review the main documents of the Catholic teaching concerning the study and interpretation of the God's Word: Providentissimus Deus, Spiritus Paraclitus, Divino Afflante Spiritu, Sacrosanctum Concilium and Dei Verbum. In addition to the precious
\end{abstract}


contributions of the Vicesimus quintus annus, Verbum Domini and Evangelii Gaudium, it will be possible to notice how, over time, Catholic teaching, driven by biblical and liturgical reform movements, created conditions for the Christian community to return in a gradual and consciously for the sacred text, above all revaluing Sacred Scripture within the liturgical celebrations. Throughout the work the teaching documents will be exposed and revisited (some documents are more well known as, for example, Dei Verbum and others not so much as Providentissimus Deus) so that it is possible to sketch an evaluation about how it is being experienced in liturgical celebrations the relationship between the Word of God and the Sacred Liturgy.

Keywords: Bible. Liturgy. Catholic Teaching.

\section{Introdução}

Caso seja possível apontar um responsável pela (re)valorização da Palavra de Deus nas celebrações litúrgicas, certamente o movimento bíblico deve ser lembrado. "Sob o impulso do movimento bíblico, autêntico dom do Espírito Santo, o magistério da igreja estimulou a comunidade cristã a voltar ao texto sagrado". ${ }^{1}$

Três encíclicas podem ser destacadas como basilares ao tentar acompanhar a evolução da relação bíblia e liturgia: Providentissimus Deus lançada em 1893 pelo Papa Leão XIII sobre os estudos bíblicos; Spiritus Paraclitus de 1920 do Papa Bento XV em comemoração do XV centenário da morte de São Jerônimo; Divino Afflante Spiritu sobre os estudos bíblicos em comemoração aos 50 anos da Providentissimus Deus, lançada em 1943 por Pio XII. Compondo o que pedimos licença para chamar de "pentateuco bíblicolitúrgico" acrescentem-se as constituições Sacrosanctum Concilium de 1963, primeiro documento aprovado no Concílio Vaticano II, sobre a sagrada liturgia e a Dei Verbum de 1965, também fruto do Vaticano II, sobre a revelação divina. Complementando com a carta Vicesimus quintus annus, de João Paulo II, escrita em 1988 em comemoração aos vinte e cinco anos da Sacrosanctum Concilium, com a exortação apostólica pós-sinodal Verbum Domini, escrita em 2010 pelo papa Bento XVI, sobre a palavra de Deus na vida da Igreja e finalizando com a exortação Evangelii Gaudium, do Papa Francisco (2013).

${ }^{1}$ TRIACCA, A. M., Bíblia e Liturgia, p. 135-151. 
Todos esses documentos do magistério católico têm em comum o desejo de que a Sagrada Escritura seja mais bem proclamada, conhecida e aprofundada nas celebrações litúrgicas. "O incremento da vida litúrgica e, por consequência, o desenvolvimento da vida cristã não poderão tornar-se realidade, se não se promover continuadamente nos fiéis e, em primeiro lugar, nos Sacerdotes, um suave e vivo amor da Sagrada Escritura". ${ }^{2}$

\section{Providentissimus Deus}

Lançada em dezoito de novembro de 1893, no décimo sexto ano do pontificado do papa Leão XIII, a encíclica Providentissimus Deus - sobre os estudos bíblicos, "inaugura" (pós Trento) uma série de documentos papais que irão se dedicar à Palavra de Deus, abrangendo a importância do estudo, da proclamação esmerada nas celebrações litúrgicas, da leitura pessoal dos fiéis etc. O papa João Paulo II, discursando no dia 23 de abril de 1993 à Pontifícia Comissão Bíblica, declarou: "A 18 de novembro de 1893, o papa Leão XIII, muito atento aos problemas intelectuais, publicava a sua Encíclica sobre os estudos da Sagrada Escritura, com a finalidade, escrevia ele, 'de os orientar de maneira que corresponda melhor às necessidades da época"." ${ }^{3}$

O trecho do discurso do papa João Paulo II oferece um resumo das ideias de Leão XIII contidas na Providentissimus Deus, ou seja, uma encíclica preocupada em indicar caminhos traçando uma metodologia segura e ortodoxa para os estudos da Palavra de Deus, de acordo com o contexto da época.

A razão principal que torna altamente recomendável este estudo, não falando já da sua excelência e do obséquio devido à palavra de Deus, está nos grandes bens que, segundo a promessa infalível do Espirito Santo, dele dimanam: - Toda a Escritura, divinamente inspirada, é útil para ensinar, para repreender, para corrigir, para instruir na justiça, a fim de que o homem de Deus seja perfeito e aparelhado para toda a obra boa. ${ }^{4}$

A encíclica faz uma revisão sobre os estudos da Sagrada Escritura, passando pelos Padres da Igreja até os dias de então. "Brilhe pois no professor de hermenêutica sagrada não só uma sólida ciência de toda a teologia, senão também um profundo conhecimento dos comentários dos Santos Padres e Doutores". 5

\footnotetext{
${ }^{2}$ VQA 8.

${ }^{3}$ JOÃO PAULO II, PP., Discurso sobre a interpretação da Bíblia na Igreja, 2.

${ }^{4} \mathrm{PD} 2$.

${ }^{5} \mathrm{PD} 18$.
} 
A respeito da atuação específica do papa Leão XIII podemos dizer que foi um verdadeiro "leão", no sentido de coragem e bravura, quando propôs e ofereceu as condições necessárias para a Igreja aprofundar os estudos da Palavra de Deus. Em 1892 concedeu uma autorização à École Biblique para a realização de estudos críticos da Bíblia e a partir da Providentissimus Deus sendo a primeira autorização formal do magistério católico para o uso de métodos críticos nos estudos bíblicos. Com a carta apostólica Vigilantiae studiique, de 30 de outubro de 1902, instituiu a Pontifícia Comissão Bíblica. Não podemos ter dúvidas de que o pontificado de Leão XIII foi fecundo, sobretudo em relação à Sagrada Escritura.

\section{Spiritus Paraclitus}

Em comemoração ao XV centenário da morte de São Jerônimo, o Papa Bento XV lançou em quinze de setembro de 1920 a carta encíclica Spiritus Paraclitus. Um documento dedicado a Jerônimo não poderia ter outro foco a não ser o estudo e interpretação da Sagrada Escritura, em continuidade aos documentos escritos por Leão XIII e Pio X.

É universalmente conhecido o lugar excelso ocupado por são Jerônimo, no qual a Igreja católica reconhece e venera o maior doutor com o qual o céu the tenha feito dom para a interpretação das Sagradas Escrituras [...]. A consciência do nosso ofício apostólico e o desejo de incrementar o estudo nobilíssimo das Escrituras, incitam-nos, de um lado, a propor como exemplo a ser imitado esse gênio, e do outro, a confirmar com a nossa apostólica autoridade e a melhor adaptação aos tempos que a Igreja atravessa hoje, as preciosíssimas diretrizes e as prescrições dadas nessa matéria por nossos predecessores de santa memória Leão XIII e Pio X. ${ }^{8}$

É belo constatar ao longo da encíclica a hermenêutica da continuidade, ou seja, como Bento XV faz constantemente referência aos seus predecessores, sobretudo Leão XIII e Pio X." "Essa doutrina formulada por São Jerônimo

${ }^{6}$ Centro de formação acadêmico Francês em Jerusalém, fundado por Dominicanos e especializado em arqueologia e exegese bíblica.

${ }^{7}$ A Pontifícia Comissão Bíblica já produziu até o presente trinta e sete documentos.

${ }^{8}$ SP 1.

9 O Papa Pio X a respeito especificamente das Sagradas Escrituras, escreveu duas cartas apostólicas: Quoniam em re biblica ("Sobre o Estudo das Escrituras nos Seminários" - 27 de março de 1906) e Vinea Electa ("Estabelecer Pontifício Instituto Bíblico" - 7 de maio de 1909); uma carta encíclica: Pascendi Dominici Gregis ("Sobre as Doutrinas dos Modernistas" - 08 de 
confirma, pois, esplendidamente e, ao mesmo tempo, explica a declaração do nosso predecessor de santa memória Leão XIII". ${ }^{10} \mathrm{Na}$ Spiritus Paraclitus são citados vários trechos retirados da Providentissimus Deus.

É um documento riquíssimo de citações do próprio Jerônimo a respeito do amor e estudo que são devidos à Sagrada Escritura, como por exemplo, no número vinte, quando o Doutor oferece algumas diretivas à virgem Eustóquio: "Seja muito assídua à leitura e ao estudo, quanto mais te é possível. Que o sono te surpreenda com os livros na mão e que a página sagrada acolha a tua cabeça debruçada pelo cansaço". ${ }^{11}$

O papa Bento XV também apresenta algumas indicações práticas e destaca os frutos espirituais que brotam a partir de um contato mais íntimo com a Sagrada Escritura. De acordo com a encíclica, o clero encontra na Escritura: a) alimento para a vida espiritual; b) argumento para a defesa dos dogmas; c) matéria para estudo assíduo. A parte final (IV) é dedicada aos frutos espirituais da Sagrada Escritura: a) amor pela Igreja e pelo papa; b) dignidade sacerdotal e graça santificante; c) união de Cristo com a sua Igreja; d) prática da vida cristã; e) amor à Eucaristia.

\section{Divino Afflante Spiritu}

A encíclica do papa Pio XII também segue as linhas dos predecessores em relação à importância dos estudos das Sagradas Escrituras.

Em 30 de setembro de 1943, por motivo do cinqüentenário da encíclica "Providentissimus Deus"; o Santo Padre Pio XII publicou a seguinte encíclica sobre os estudos bíblicos. Por sua extensão, e pela admirável clareza com que expõe as normas que devem ser observadas no uso da Sagrada Escritura, o importante documento adquire o alcance de uma verdadeira Carta Magna em matéria de estudos e apostolado bíblicos. ${ }^{12}$

Cinquenta anos após a Providentissimus Deus de Leão XIII, a Divino Afflante Spiritu também é dedicada aos estudos bíblicos. E pela nota acima é possível perceber o quão importante e profunda é a encíclica do papa Pio XII, que também faz questão de relembrar a relevância de seus predecessores no

setembro de 1907) e um motu próprio: Carta Praestantia Scripturae Sacrae ("Sobre as decisões da Comissão Bíblica" - 18 de novembro de 1907).

${ }^{10} \mathrm{SP} 8$.

${ }^{11}$ SP 20

${ }^{12}$ Retirado da nota explicativa apresentando o motivo da encíclica Providentissimus Deus. 
campo de estudo da Sagrada Escritura. Logo na primeira parte a encíclica destaca a solicitude de Leão XIII e sucessores pelos estudos bíblicos. É possível constatar mais uma vez a hermenêutica da continuidade para o maior benefício da Igreja e dos fiéis.

A respeito de Leão XIII, o papa Pio XII recorda a sua doutrina sobre a inerrância bíblica; o impulso dado aos estudos bíblicos com a École Biblique e a instituição da Pontifícia Comissão Bíblica. Sobre Pio X a Divino Afflante Spiritu destaca o programa de estudos bíblicos e o Instituto bíblico em Roma. Comenta também sobre a atuação de Pio XI em relação aos graus acadêmicos obrigatórios e a designação do Mosteiro de S. Jerônimo para a revisão da Vulgata.

Em linhas gerais a Divino Afflante Spiritu dedica maior atenção às questões ligadas aos critérios hermenêuticos para a interpretação da bíblia, começando com uma apresentação geral de como estavam os estudos na época de lançamento da encíclica.

Nesses cinqüenta anos as condições dos estudos bíblicos e ciências auxiliares; não há quem o não veja, mudaram consideravelmente. Assim, para não falar de outras coisas, quando nosso predecessor publicou a Encíclica Providentissimus Deus, apenas um ou outro lugar da Palestina se tinha começado a explorar com escavações orientadas nesse sentido. Agora tais explorações têm-se multiplicado enormemente e fazem-se com métodos mais rigorosos e arte aperfeiçoada pela experiência, de modo que os resultados são muito mais abundantes e certos. ${ }^{13}$

O papa Pio XII em linhas gerais não demonstrou preocupação em apontar erros no trabalho de interpretação da Sagrada Escritura, mas destacou alguns pontos essenciais para o desempenho da função do exegeta católico, como por exemplo, maior dedicação aos estudos da bíblia a partir de suas línguas originais, o hebraico e o grego; a importância da interpretação da bíblia em seu sentido literal ou espiritual; não desprezar, na interpretação da bíblia, a Tradição da Igreja, principalmente a partir dos estudos dos Santos Padres, dentre outras recomendações.

\section{Sacrosanctum Concilium}

Uma senhora constituição! É assim que em todos os sentidos podemos chamar a Constituição Dogmática Sacrosanctum Concilium sobre a sagrada liturgia. Em um primeiro sentido é uma senhora, pois no dia quatro de dezembro

${ }^{13}$ DAS 11. 
de 2018 completou 55 anos da sua promulgação por Paulo VI, sendo o primeiro documento aprovado no Concílio Vaticano II. E é senhora também no sentido de respeito, imponência, e, sobretudo pela relevância que teve e continua tendo para a Sagrada Liturgia, mesmo que em alguns casos ainda incompreendida e mal aplicada. "Foi a primeira vez que um Concílio Ecumênico tratou exaustivamente da Sagrada Liturgia. O Concílio de Trento tentou uma reforma. Por vários motivos ela só pôde ser parcial". ${ }^{14}$

Qual o principal objetivo da Sacrosanctum Concilium, considerada a pérola da teologia do Vaticano II? Uma reforma preocupada com as rubricas? Seria apenas uma reforma externa das celebrações litúrgicas, para torná-las mais "atraentes"? Ou podemos supor que o objetivo da constituição era atingir e reformar algo bem mais profundo?

O Sacrossanto Concílio propõe-se fomentar sempre mais a vida cristã entre os fieis; acomodar melhor às necessidades de nossa época as instituições que são suscetíveis de mudanças; favorecer tudo o que possa contribuir para a união dos que crêem em Cristo; e promover tudo o que conduz ao chamamento de todos ao seio da Igreja. Por isso julga ser seu dever cuidar de modo especial da reforma e do incremento da Liturgia. ${ }^{15}$

Logo no primeiro número é possível constatar os reais objetivos do documento: estimular a vida cristã dos fiéis; realizar as mudanças necessárias para uma melhor adequação à época; favorecer o ecumenismo; levar todos até o seio da Igreja. Tudo isso deveria ser realizado através da reforma e desenvolvimento da Liturgia.

O empenho dos padres conciliares em produzir um documento que tratasse da Sagrada Liturgia de maneira que pudesse render frutos autênticos para os fiéis na Igreja, contou certamente com o apoio de diversos movimentos que pretendiam voltar às fontes em relação à renovação litúrgica. "Entre eles surgiu o Movimento Litúrgico de volta às fontes, em busca de uma compreensão teológica de Liturgia realçando particularmente a necessidade de uma participação de todos os cristãos na Sagrada Liturgia". ${ }^{16}$

De maneira específica a Sacrosanctum Concilium trata de forma extraordinária a respeito da relação entre a Sagrada Escritura e a Liturgia, deixando bem claro que não pode haver uma ruptura entre a Palavra de Deus e as celebrações da Igreja. "Para que apareça claramente que na Liturgia as

\footnotetext{
${ }^{14}$ BECKHÄUSER, A., Sacrosanctum Concilium, p. 7.

${ }^{15} \mathrm{SC} 1$.

${ }^{16}$ BECKHÄUSER, A., Sacrosanctum Concilium, p. 8.
} 
cerimônias e as palavras estão intimamente conexas. Nas celebrações litúrgicas restaure-se a leitura da Sagrada Escritura mais abundante, variada e apropriada". ${ }^{17}$ De acordo com o Alberto Beckhäuser a partir da Sacrosanctum Concilium "a própria Palavra de Deus foi vista sob nova perspectiva à luz da Economia da Salvação". ${ }^{18}$ Uma reforma litúrgica autêntica e frutuosa que realmente se preocupe com o desenvolvimento da vida cristã, não pode deixar despercebida a necessidade vital de um "suave e vivo amor da Sagrada Escritura", ${ }^{19}$ seja por parte dos sacerdotes como de todo os fiéis.

No dia 25 de janeiro de 1964, o Papa Paulo VI apresentou a Carta Apostólica Sacram Liturgiam (Motu proprio), determinando que entrasse em vigor algumas disposições da Sacrosanctum Concilium. "Todavia, como entre as normas da Constituição há algumas que já se podem efetivar, desejamos que essas entrem imediatamente em vigor, a fim de que as almas dos fiéis não sejam privadas por mais tempo dos frutos de graça que daí se esperam". ${ }^{20}$

\section{Dei Verbum}

A Constituição Dogmática Dei Verbum - sobre a revelação divina, foi um dos últimos documentos a ser aprovado (18 de novembro de 1965) no Concílio Vaticano II. De acordo com Santana, a Dei Verbum é considerada a “"carta magna' da revelação contida na Palavra de Deus". ${ }^{21}$ Não seria exagerado afirmar que a Dei Verbum exerceu influência direta para que a Palavra de Deus voltasse a ser o coração e impulsionadora da ação missionária da Igreja. "Esta Constituição Dogmática do Concílio Vaticano II foi um forte estímulo para que o uso diuturno da Escritura voltasse na vida da Igreja". ${ }^{22}$ Não pode haver evangelização sem uma íntima relação com a Palavra de Deus.

É interessante notar que embora fale exaustivamente a respeito da Palavra de Deus, a Dei Verbum não é especificamente um documento sobre a bíblia, mas sim sobre a Revelação Divina, que acontece através da Sagrada Escritura e Tradição. "Por isso, seguindo as pegadas dos Concílios Tridentino e Vaticano I, este Santo Concílio se propõe expor a genuína doutrina acerca da

${ }^{17} \mathrm{SC} 35$.

${ }^{18}$ BECKHÄUSER, A., Sacrosanctum Concilium, p. 12.

${ }^{19} \mathrm{SC} 24$.

${ }^{20}$ PAULO VI, PP., Carta Apostólica Sacram Liturgiam.

${ }^{21}$ SANTANA, L. F. R., Bíblia e Liturgia (2017), p. 244.

${ }^{22}$ LOPES, G., Dei Verbum, p. 51. 
Revelação Divina e de sua transmissão a fim de que pelo anúncio da salvação, o mundo inteiro ouvindo creia, crendo espere, esperando ame". ${ }^{23}$

Para compreender um pouco mais a relevância da Dei Verbum para a vida da Igreja é necessário lembrar que o ambiente do período de elaboração e lançamento da Constituição Dogmática era cercado por resquícios da crise modernista. "Quase tudo estava parado e pouca coisa parecia se mover. A Dei Verbum vai ser uma brisa de ar puro". ${ }^{24}$ Diante de tal afirmação é difícil não fazer memória do Papa João XXIII, que durante o seu pontificado desejava um ar puro na Igreja.

O capítulo III trata especificamente sobre a inspiração divina da sagrada escritura e sua interpretação, destacando também a importância de um bom trabalho por parte dos exegetas católicos. Assim como nos outros documentos do magistério, já comentados neste trabalho, é perfeitamente claro o cuidado e atenção dedicados pela Igreja na interpretação da Sagrada Escritura.

Mas como a Sagrada Escritura deve ser também lida e interpretada naquele mesmo Espírito em que foi escrita, para apreender com exatidão o sentido dos textos sagrados, deve-se atender com não menor diligência ao conteúdo e à unidade de toda a Escritura, levada em conta a Tradição viva da Igreja toda e a analogia da fé. É dever dos exegetas esforçar-se dentro destas diretrizes para entender e expor com maior aprofundamento o sentido da Sagrada Escritura, a fim de que, por seu trabalho como que preparatório, amadureça o julgamento da Igreja. ${ }^{25}$

A Dei Verbum destaca de forma belíssima a importância da Sagrada Escritura dentro das celebrações litúrgicas e a relação inseparável entre ambas. "A Igreja sempre venerou as divinas Escrituras, como também o próprio Corpo do Senhor; sobretudo na sagrada Liturgia, nunca deixou de tomar e distribuir aos fiéis, da mesa tanto da Palavra de Deus como do Corpo de Cristo, o pão da vida". ${ }^{26} \mathrm{Na}$ mesma linha, Triacca ressalta a relação entre a Palavra de Deus e Sagrada Liturgia: "ao participar de uma celebração da Palavra, os cristãos sentem vontade de participar da celebração da eucaristia, que é a realização máxima de toda Palavra proclamada" ${ }^{27}$

Os fiéis também são exortados para que se alimentem da Santa Palavra a fim de terem maior intimidade com o Senhor e consequente crescimento na

${ }^{23}$ DV 1.

${ }^{24}$ LOPES, G., Dei Verbum, p. 57.

${ }^{25}$ DV 12.

${ }^{26}$ DV 21.

${ }^{27}$ TRIACCA, A. M., Bíblia e Liturgia, p. 147. 
vida espiritual. Uma leitura assídua e meditada da Sagrada Escritura certamente favorece uma participação nas celebrações litúrgicas ainda mais frutuosa.

Com efeito, nos Livros Sagrados, o Pai que está nos céus vem amorosamente ao encontro dos seus filhos, para conversar com eles; e é tão grande a força e virtude da Palavra de Deus, que fornece à Igreja o apoio vigoroso, aos filhos da Igreja a solidez na fé, e constitui alimento da alma, fonte pura e perene da vida espiritual. ${ }^{28}$

Diante de um mundo cada vez mais relativista, nunca foi tão necessária uma palavra que transmita uma verdade absoluta, segura e que realmente toque no íntimo de cada pessoa com o coração aberto a acolhê-la. Sem dúvidas de que a única palavra com este condão é a Palavra de Deus, que é sempre viva e eficaz $(\mathrm{Hb} 4,12)$ e a Dei Verbum indica caminhos para que a relação com a Sagrada Escritura seja cada vez mais profunda e frutuosa.

\section{Vicesimus quintus annus}

Em comemoração aos vinte e cinco anos da promulgação da Sacrosanctum Concilium, o papa João Paulo II escreveu a Carta Apostólica Vicesimus quintus annus. A carta destaca logo no começo que o papa sempre teve a preocupação em colocar em prática as diretrizes do Vaticano II e recorda que ele mesmo já tinha desenvolvido alguns aspectos, à luz do Concílio, a respeito da Liturgia. "Desde os inícios do nosso ministério pastoral na Sé de Pedro, sempre tivemos a preocupação de insistir na importância que continua a ter o Segundo Concílio Ecumênico do Vaticano e assumimos o compromisso formal de lhe dar a devida aplicação". ${ }^{29}$

A carta de João Paulo II faz uma breve análise apontando as fontes da Sacrosanctum Concilium e os princípios que nortearam os rumos da Constituição. Neste trabalho apresentamos um enfoque na parte relativa à leitura da Palavra de Deus. O papa destaca basicamente os números trinta e quatro e trinta e cinco, como fundamentais da Sacrosanctum Concilium ligados à Sagrada Escritura na Liturgia.

João Paulo II reconhece que a Palavra de Deus tinha uma nova dimensão de leitura e conhecimento nas comunidades, e grande parte deste avanço era graças ao documento sobre a Sagrada Liturgia do Vaticano II, porém ainda era preciso avançar. "A Palavra de Deus é atualmente mais conhecida no seio da comunidade

\footnotetext{
${ }^{28}$ DV 21.

${ }^{29}$ VQA 2.
} 
cristã, mas uma renovação autêntica continua a apresentar ainda e sempre novas exigências". ${ }^{30}$ A Vigesimus quintus annus reconhece como a reforma litúrgica foi importante para uma (re)valorização da Palavra de Deus nas celebrações:

Por isso há que dar graças a Deus pela passagem do seu Espírito na Igreja, qual foi a renovação litúrgica, pela mesa da Palavra de Deus, doravante posta abundantemente para todos, pelo esforço imenso que se fez em todo o mundo, com o fim de dotar o povo cristão de traduções da Bíblia, do Missal e dos outros livros litúrgicos. ${ }^{31}$

Em relação ao futuro da renovação, João Paulo II destaca a importância e necessidade de uma contínua formação bíblica e litúrgica, destacando que se trata da tarefa mais urgente. "A tarefa que se apresenta mais urgente é a da formação bíblica e litúrgica do Povo de Deus: dos pastores e dos fiéis". ${ }^{32} \mathrm{O}$ papa deixa bem claro que tal formação, para os sacerdotes, deve começar nos "Seminários e Casas religiosas e continuar ao longo de toda a vida sacerdotal. Esta mesma formação, adaptada à condição que lhes é própria, é indispensável também para os leigos". ${ }^{33}$

\section{Verbum Domini}

Se antes comentamos que a Sacrosanctum Concilium é a pérola da teologia do Vaticano II, pedimos licença para também comentar que a Verbum Domini é uma "joia preciosa" do pontificado de Bento XVI, sobre a palavra de Deus na vida e na missão da Igreja. A exortação apostólica pós-sinodal é fruto da XII Assembleia Geral Ordinária do Sínodo dos Bispos, realizado entre os dias 5 e 26 de outubro de 2008 no Vaticano, que teve como tema "A Palavra de Deus na vida e na missão da Igreja”.

Foi uma experiência profunda de encontro com Cristo, Verbo do Pai, que está presente onde dois ou três se encontram reunidos em seu nome (Mt $18,20)$. Com esta Exortação apostólica pós-sinodal, acolho de bom grado o pedido que me fizeram os Padres de dar a conhecer a todo o Povo de Deus a riqueza surgida naquela reunião vaticana e as indicações emanadas do trabalho comum. ${ }^{34}$

\footnotetext{
${ }^{30}$ VQA 8.

${ }^{31}$ VQA 12.

${ }^{32}$ VQA 15.

${ }^{33}$ SC 19.

${ }^{34} \mathrm{VD} 1$.
} 
A exortação dividida em três partes dedica o número 52 para tratar especificamente da Palavra de Deus na sagrada liturgia. "Considerando a Igreja como 'casa da Palavra', deve-se antes de tudo dar atenção à liturgia sagrada". Seguindo a linha dos documentos anteriores, que também abordaram a questão, a Verbum Domini ratifica a relação intrínseca entre a Sagrada Escritura e Liturgia, pois a segunda está complemente tomada pela primeira. "Cada ação litúrgica está, por sua natureza, impregnada da Sagrada Escritura". ${ }^{36}$

A Dei Verbum e a Sacrosanctum Concilium são citadas várias vezes na Verbum Domini, tornando explícita na prática a expressão utilizada pelo papa Bento XVI ao longo do seu pontificado: hermenêutica da continuidade. "É enorme a importância da Sagrada Escritura na celebração da Liturgia". ${ }^{37}$ A exortação apostólica também destaca a importância de pastores e fiéis estudarem continuamente a Sagrada Escritura, como já era desejo dos documentos anteriores.

Por isso exorto os Pastores da Igreja e os agentes pastorais a fazer com que todos os fiéis sejam educados para saborear o sentido profundo da Palavra de Deus que está distribuída ao longo do ano na liturgia, mostrando os mistérios fundamentais da nossa fé. Também disto depende a correta abordagem da Sagrada Escritura. ${ }^{38}$

A Verbum Domini não esgota, mas coloca um diadema no entendimento a respeito da relação inseparável entre Palavra de Deus e Liturgia, pois esta "sustenta-se fundamentalmente na Palavra de Deus, razão pela qual se transforma em um acontecimento sempre novo e atual". ${ }^{39}$

\section{Evangelii Gaudium}

No seu pontificado o Papa Francisco já se pronunciou diversas vezes a respeito da importância da Sagrada Escritura, não apenas na vivência pessoal de cada cristão, mas também na relação com a Liturgia. Especificamente na exortação apostólica Evangelii Gaudium, escrita em 2013, o papa enfatiza a grande importância de tal relacionamento.

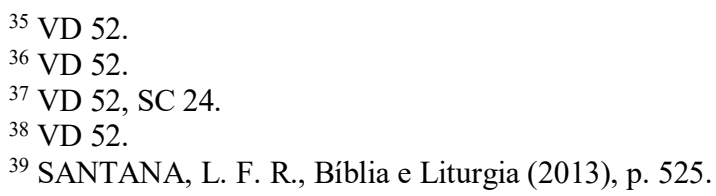


Não é só a homilia que se deve alimentar da Palavra de Deus. Toda a evangelização está fundada sobre esta Palavra escutada, meditada, vivida, celebrada e testemunhada. A Sagrada Escritura é fonte da evangelização. Por isso, é preciso formar-se continuamente na escuta da Palavra. ${ }^{40}$

A escuta da Palavra de Deus acontece de forma solene no interior de toda celebração litúrgica e deve produzir frutos em todas as ações pastorais da Igreja. Uma comunidade que não se alimenta adequadamente da mesa da Palavra e da Eucaristia, sentir-se-á enfraquecida na missão de testemunhar O Ressuscitado. "A Palavra de Deus ouvida e celebrada, sobretudo na Eucaristia, alimenta e reforça interiormente os cristãos e torna-os capazes de um autêntico testemunho evangélico na vida diária". ${ }^{41}$

A Evangelii Gaudium também retoma a orientação dos documentos magisteriais que orientam sobre a importância do estudo das Sagradas Escrituras para o fortalecimento da comunidade cristã, destacando a relação entre evangelização e Palavra de Deus: "O estudo da Sagrada Escritura deve ser uma porta aberta para todos os crentes. É fundamental que a Palavra revelada fecunde radicalmente a catequese e todos os esforços para transmitir a fé. ${ }^{42}$

\section{Conclusão}

Da Providentissimus Deus à Evangelii Gaudium o magistério católico sempre buscou uma (re)valorização da Palavra de Deus, seja através de estudos, instituindo por exemplo a Pontifícia Comissão Bíblica, ou concedendo autorizações para estudos críticos da Palavra, incentivando também novas formas de exegese. A relação entre Sagrada Escritura e Sagrada Liturgia não foi deixada de lado também neste percurso. Não que a Igreja por um determinado período da história tenha deixado de lado essa relação, mas era preciso um novo ânimo, ou uma renovação com o objetivo de estreitar o nexo entre Palavra de Deus e Sagrada Liturgia, fazendo com que pudessem caminhar de maneira harmônica, produzindo frutos necessários para o aperfeiçoamento e crescimento espiritual do povo de Deus. O desejo do magistério, a partir dos documentos apresentados, sempre foi colocar a Palavra de Deus no lugar de excelência que deve ocupar, seja na vida cotidiana dos fiéis e da própria Igreja, assim como nas celebrações litúrgicas.

\footnotetext{
${ }^{40} \mathrm{EG} 174$.

${ }^{41}$ EG 174.

${ }^{42}$ EG 175.
} 
Uma linha do tempo é útil para ilustrar o caminho percorrido até os dias de hoje em relação a Palavra de Deus e a Liturgia:

1893 - Providentissums Deus - Sobre os estudos bíblicos - Papa Leão XIII; 1920 - Spiritus Paraclitus - XV Centenário morte de São Jerônimo Papa Bento XV;

1943 - Divino Afflante Spiritu - Sobre os estudos bíblicos - Papa Pio XII; 1963 - Sacrosanctum Concilium - Sobre a Sagrada Liturgia - Papa Paulo VI; 1965 - Dei Verbum - Sobre a Revelação Divina - Papa Paulo VI;

1988 - Vicesimus quintus annus - 25 anos da Sacrosanctum Concilium - Papa João Paulo II;

2010 - Verbum Domini - Sobre a Palavra de Deus na vida e missão da Igreja - Papa Bento XVI;

2013 - Evangelii Gaudium - Sobre o anúncio do Evangelho no mundo atual - Papa Francisco.

De 1893, ano de lançamento da Providentissimus Deus, até a Evangelii Gaudim (2013) temos um caminho percorrido de cento e vinte anos, por isso é essencial ao analisar os documentos levar em consideração o contexto de cada época, sobretudo no sentido eclesial, pois só assim será possível compreender a essência das mensagens contidas em cada documento. Agindo assim, tesouros contidos na Palavra de Deus poderão ser descobertos e utilizados para incrementar e robustecer a vida dos fiéis, sobretudo a partir da Sagrada Liturgia. "Para que a mesa da Palavra de Deus seja preparada, com maior abundância, para os fiéis, abram-se largamente os tesouros da Bíblia, de modo que, dentro de certo número de anos, sejam lidas ao povo as partes mais importantes da Sagrada Escritura". ${ }^{43}$

As celebrações litúrgicas estão impregnadas da Palavra de Deus, e esta por sua vez, revela de forma profunda e dá sentido àquilo que é celebrado fazendo com que os participantes sejam inseridos no Mistério Pascal. Com a compreensão adequada é possível que os fiéis consigam levar para suas atividades cotidianas a mensagem que brota da perfeita integração entre a Palavra de Deus e a Sagrada Liturgia.

Do Papa Leão XIII a Francisco (da Providentissimus Deus à Evangelii Gaudium) um longo caminho foi trilhado, mas muitos passos ainda precisam ser dados, de modo que o magistério católico precisa continuar o trabalho iniciado na seara da Palavra de Deus e Sagrada Liturgia. A proclamação da

${ }^{43}$ SC 51. 
Palavra de Deus nas celebrações litúrgicas, que compõem a vida da Igreja, não pode ser negligenciada como se fosse apenas um complemento ao rito realizado, muito pelo contrário, pois em estrita união com a Sagrada Eucaristia formam o coração da liturgia e da própria vida da Igreja. A Sagrada Liturgia é o meio por excelência onde os fiéis devem ouvir a Palavra de Deus para que possam crer, esperar e amar. A fim de cumprir com êxito a missão evangelizadora da Igreja, ao magistério cabe a reta orientação dos pastores e fiéis no que diz respeito à relação intrínseca entre Palavra de Deus e Liturgia, não deixando nunca de apontar o caminho para uma perene e consciente renovação, que sempre deverá ter como objetivo o crescimento em graça e sabedoria do povo de Deus.

\section{Referências bibliográficas}

BECKHÄUSER, A. Sacrosanctum Concilium: texto e comentário. São Paulo: Paulinas, 2012.

BENTO XV, PP. Carta Encíclica Spiritus Paraclitus, em comemoração ao XV centenário da morte de São Jerônimo. Disponível em: $<$ https://w2.vatican.va/content/benedict-xv/en/encyclicals/documents/hf_benxv_enc_15091920_spiritus-paraclitus.html >. Acesso em: 18 nov. 2018.

BENTO XVI, PP. Exortação Apostólica pós-sinodal Verbum Domini, sobre a Palavra de Deus na vida e missão da Igreja. Disponível em: $<$ http://w2.vatican.va/content/benedict-

xvi/pt/apost_exhortations/documents/hf_ben-xvi_exh_20100930_verbumdomini.html>. Acesso em: 18 nov. 2018.

CONCÍlLIO VATICANO II. Constituição Dogmática Dei Verbum, 18 de novembro de 1965. In: COMPÊNDIO DO VATICANO II. Constituições, Decretos, Declarações. 29.ed. Petrópolis: Vozes, 2000. p. 121-139.

CONCÍLIO VATICANO II. Constituição Sacrosanctum Concilium, 4 de dezembro de 1963. In: COMPÊNDIO DO VATICANO II. Constituições, Decretos, Declarações. 29. ed. Petrópolis: Vozes, 2000. p. 259-306.

FRANCISCO, PP. Exortação Apostólica Evangelii Gaudium, sobre o anúncio do Evangelho no mundo atual. Brasília: Edições CNBB, 2013.

JOÃO PAULO II, PP. Carta Apostólica Vicesimus quintus annus. Disponível em: $<$ https://w2.vatican.va/content/john-paul-ii/en/apost_letters/1988/documents/hf_jpii_apl_19881204_vicesimus-quintus-annus.html>. Acesso em: 07 out. 2018. 
JOÃO PAULO II, PP. Discurso sobre a interpretação da Bíblia na Igreja (23 de abril de 1993). Disponível em: <http://w2.vatican.va/content/john-paulii/pt/speeches/1993/april/documents/hf_jp-ii_spe_19930423_dueanniversari.html>. Acesso em: 20 mar. 2019.

LEÃO XIII, PP. Carta Encíclica Providentissiumus Deus, sobre os estudos bíblicos. Disponível em: $<$ https://w2.vatican.va/content/leo-xiii/pt/encyclicals/documents/hf_1xiii_enc_18111893_providentissimus-deus.html>. Acesso em: 08 out. 2018.

LOPES, G. Dei Verbum: texto e comentário. São Paulo: Paulinas, 2012.

PAULO VI, PP. Carta Apostólica Sacram Liturgiam. Disponível em: $<$ http://w2.vatican.va/content/paul-vi/en/motu_proprio/documents/hf_pvi_motu-proprio_19640125_sacram-liturgiam.html> Acesso em: 12 out. 2018.

PIO XII, PP. Carta Encíclica Divino Afflante Spititu. Disponível em: $<$ http://w2.vatican.va/content/pius-xii/pt/encyclicals/documents/hf_pxii_enc_30091943_divino-afflante-spiritu.html\#fn1>. Acesso em: 19 mar. 2019. SANTANA, L. F. R. Bíblia e Liturgia: da Dei Verbum à Verbum Domini. Atualidade Teológica, v. 21, n. 56, p. 243-263, mai./ago. 2017. Disponível em: $<$ https://www.maxwell.vrac.puc-rio.br/30367/30367.PDF>. Acesso em: 19 mar. 2019.

SANTANA, L. F. R. Bíblia e Liturgia. Atualidade Teológica, v. 17, n. 45, p. 510-530, set./dez. 2013. Disponível em: <https://www.maxwell.vrac.pucrio.br/22916/22916.PDF>. Acesso em: 19 mar. 2019.

TRIACCA, A. M. Bíblia e Liturgia. In: SARTORE, D.; TRIACCA, A. M. (Orgs.). Dicionário de Liturgia. São Paulo: Paulus, 1992. p. 135-151.

\section{Marcelo Massao Osava}

Mestrando em Teologia pela Pontifícia Universidade Católica do Rio de Janeiro

Rio de Janeiro / RJ - Brasil

E-mail: marcelorb@gmail.com

Recebido em: 29/03/19

Aprovado em: 18/12/19 